\title{
Краевые ледниковые образования в бассейне р. Цага (западная часть Кольского полуострова)
}

\author{
Вашков А.А., Носова О.Ю., Толстобров Д.С. \\ Геологический институт КНЦ РАН, Anamumbl,vashkov@geoksc.apatity.ru
}

\begin{abstract}
Аннотация. В строении грядового и холмисто-грядового ледникового рельефа в бассейне р. Цага установлены насыпные морены с гляциодислокациями, которые залегают на покровных базальных моренах. Структурные исследования деформаций в толще морен указывают на давление ледника в северо-восточном направлении. Изученный ледниковый рельеф формировался у ледникового края на склонах поднятий доледниковой поверхности. В роли одного из таких поднятий выступал массив Панских Тундр. Насыпные морены с гляциодислокациями относятся к комплексу конечно-моренного рельефа одной из фаз сокращения последнего ледникового покрова.
\end{abstract}

Ключевые слова: конечно-моренные образования, насыпная морена, базальная морена, гляциодислокации, дегляциация, ледниковый рельеф.

\section{Ice marginal formations in the Tsaga River Basin (the west part of the Kola Peninsula)}

\author{
Vashkov A., Nosova O., Tolstobrov D. \\ Geological Institute of the Kola Science Centre of RAS, Apatity,vashkov@geoksc.apatity.ru
}

\begin{abstract}
Waste moraines with glaciodislocations were found in the structure of the ridge and hummockyridge glacial relief in the Tsaga River Basin. They lie on the basal moraines. Structural studies of the deformations in the moraine deposits indicate that ice moved to the north-east. The studied glacial relief formed near the ice margin on the slopes of bedrock uplifts. One of the uplifts was the Pana Tundra. The waste moraines with glaciodislocations relate to the complex of ice marginal moraine relief of the recession phase of the last ice cover.

Key words: end moraine formations, waste moraine, basal moraine, glaciodislocations, deglaciation, glacial relief.
\end{abstract}

В настоящий момент многочисленными исследованиями четвертичных отложений и ледникового рельефа в Кольском регионе установлено два основных участка локализации краевых ледниковых образований (Стрелков и др., 1976; Евзеров, Николаева, 2000; Kolka et al., 2008). К первому относится система субширотных краевых образований вдоль беломорского побережья Кольского полуострова - Терские Кейвы (Hätterstrand et al, 2007). Ко второму принадлежат субмеридиональные краевые образования, простирающиеся вдоль условной линии Териберка - Ревда - Ловозерские Тундры (исключая) - Панские Тундры (исключая) - оз. Вялозеро (Евзеров, Николаева, 2000; Ekman, Ilyin, 1991). Указанные участки краевых ледниковых образований выделены по комплексу методов, доминирующими среди которых были анализ аэрофотоматериалов, космических изображений и топографических карт (Евзеров, 2015; Hätterstrand et al, 2007). Геологическое строение краевых образований было исследовано по немногочисленным ключевым участкам и отдельным разрезам (Евзеров и др, 1993; Kolka et al., 2008). Продолжение работ по исследованию ледниковых структур в пределах участков развития краевых образований открывает новые закономерности развития и деградации последнего оледенения в регионе, а также уточняет поисковые критерии минерально-строительного сырья в регионе.

В исследовании применялся комплекс геолого-геоморфологических методов. Изучались структурно-текстурные особенности ледниковых и водно-ледниковых отложений. Гранулометрический анализ проводился с помощью набора стандартных сит диаметром 1-10 мм. Цвет отложений определялся при помощи колориметрической системы Munsell Soil Color Charts. Детальное исследование текстуры ледниковых отложений производилось с помощью массовых замеров плоскост- 
ных (плоскости сланцеватости, слоистости) и линейных (длинные оси галек и валунов) элементов (Аболтиньш, 1989). Результаты были обработаны при помощи программы OpenStereo 0.1.2, структурные диаграммы строились на нижней полусфере равноплощадной сетки Шмидта. Исследование ледниковых форм рельефа заключалось в определении их морфологических характеристик: длины, высоты, крутизны склонов, ширины и ориентировки гребней гряд. Корреляция краевых образований проводилась с помощью анализа морфометрических показателей рельефа с использованием цифровой модели рельефа ArcticDEM разрешением 2 м.

Новый фактический материал был получен в ходе полевых работ в 2019-2020 гг. Был исследован грядовый рельеф в среднем и верхнем течении р. Цага (рис. 1). Гряды расположены на абсолютных отметках 175-205 м над уровнем моря (н.у.м.). Они находятся на склонах массива Панские Тундры и на прилегающей с северо-запада равнине. По одному из мнений, данный рельеф относится к напорным конечно-моренным грядам внешней полосы маргинального пояса II, который формировался в беллинге и среднем дриасе (Евзеров, Николаева, 2000). По другому мнению, данная территория относится к холмистому моренному рельефу предположительно лужской фазы сокращения последнего ледникового покрова (Ekman, Ilyin, 1991). На Государственной геологической карте на исследуемой территории представлены краевые образования сразу двух фаз: лужской и невской, которые сближаются на расстояние 2-5 км у западного склона Панских Тундр (Государственная геологическая карта...2012).

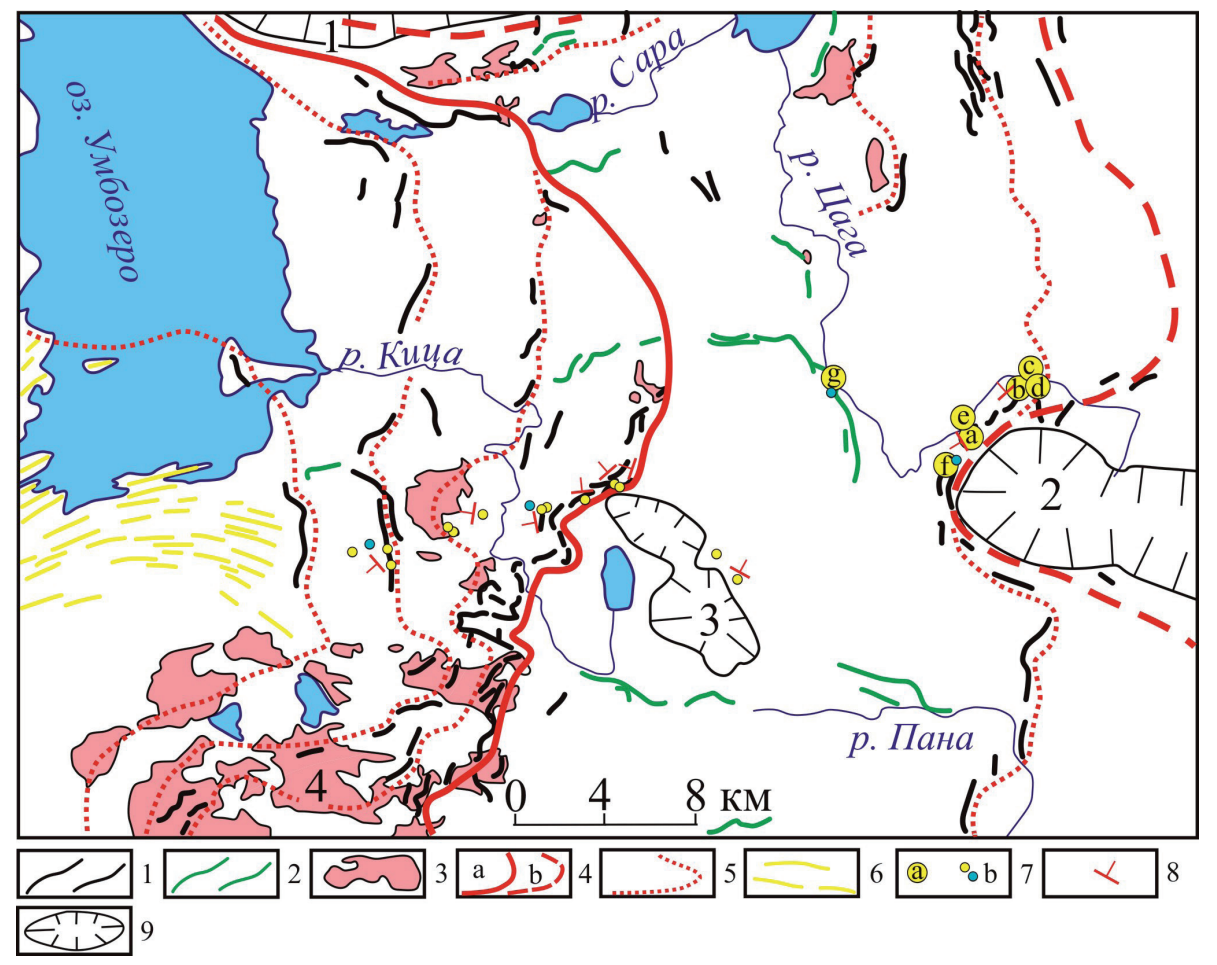

Рис. 1. Схема краевых ледниковых образований в бассейнах рек Кица и Цага: 1 - моренные гряды; 2 - озы; 3 - моренный грядово-кольцевой рельеф; 4 - полосы краевых образований ранга фазы сокращения ледникового покрова; 5 - то же, ранга осцилляции; 6 - друмлины (друмлиноиды); 7 - пункты исследования ледниковых осадков (a) и озерных осадков (b); 8 - направления давления льда по результатам исследования гляциоструктур; 9 - коренные массивы (цифры на карте: 1 - Ловозерские Тундры, 2 - Панские Тундры, 3 - Фёдорова Тундра и г. Инчьявр, 4 - Мунозерская островная возвышенность).

Fig. 1. Scheme of the ice marginal formations in the Kitsa and Tsaga Rivers Basins: 1 - moraine ridges; 2 - eskers; 3 - veiki (ring-ridge) moraine relief; 4 - belts of the ice marginal formations of recession phase of ice cover; 5 - the same, of oscillation phase; 6 - drumlins (drumlinoids); 7 - places of studying of glacial deposits (a) and lacustrine sediments (b); 8 - directions of ice movement based on the results of investigation of the glaciostructures; 9 - bedrock massifs (numerals on the map: 1 - Lovozero Tundra, 2 - Pana Tundra, 3 - Fyodorova Tundra and Inchyavr Mountain, 4 - Munozero Insular Upland). 
В ходе полевых работ было изучено строение одной из гряд на северо-западном склоне г. Каменик (Панские Тундры). Гряда овальная в плане, длиной 0.3 км, шириной до 0.14 км и абсолютной отметкой вершины до 196.7 м н.у.м. Склоны гряды ассиметричные, северо-западный склон выше и круче, чем юго-восточный. В шурфе (N 67³2'44', Е $35^{\circ} 15^{\prime} 49^{\prime}$ ', пункт а на рис. 1) размерами $4.8 \times 1.3$ м и глубиной до 2.3 м вскрываются формообразующие отложения, разделенные на 3 блока (рис. 2, А, Б, В):

Блок А: переслаивание песка тонкозернистого (т.з.), однородного, уплотненного, оливковосерого цвета с песками мелкозернистыми (м.з.) серо-коричневыми и песками разнозернистыми (р.з.), преимущественно среднезернистыми (с.з.), с редким гравием, светло-оливково-коричневого цвета. Первичная слоистость отложений в целом имеет выдержанное падение по азимуту $75^{\circ}$ под углом $30^{\circ}$. Мощность осадков в блоке - свыше 2.3 м.

Блок Б: песок м.з., однородный, сортированный, слоистый. Слоистость выражена за счет изменения цвета песка от светло-оливково-серого до серого. Толщина прослоев разной окраски - до 1.5 см. Слоистость в целом субпараллельная, имеет уклон по азимуту $102^{\circ}$ под углом $29^{\circ}$. Мощность песков видимая - до 1 м.

Блок В: переслаивание двух разностей песков. Первая: пески с.з., однородные, уплотненные, с примесью песка крупнозернистого (к.з.) с зернами гравия, светло-оливково-коричневого цвета,

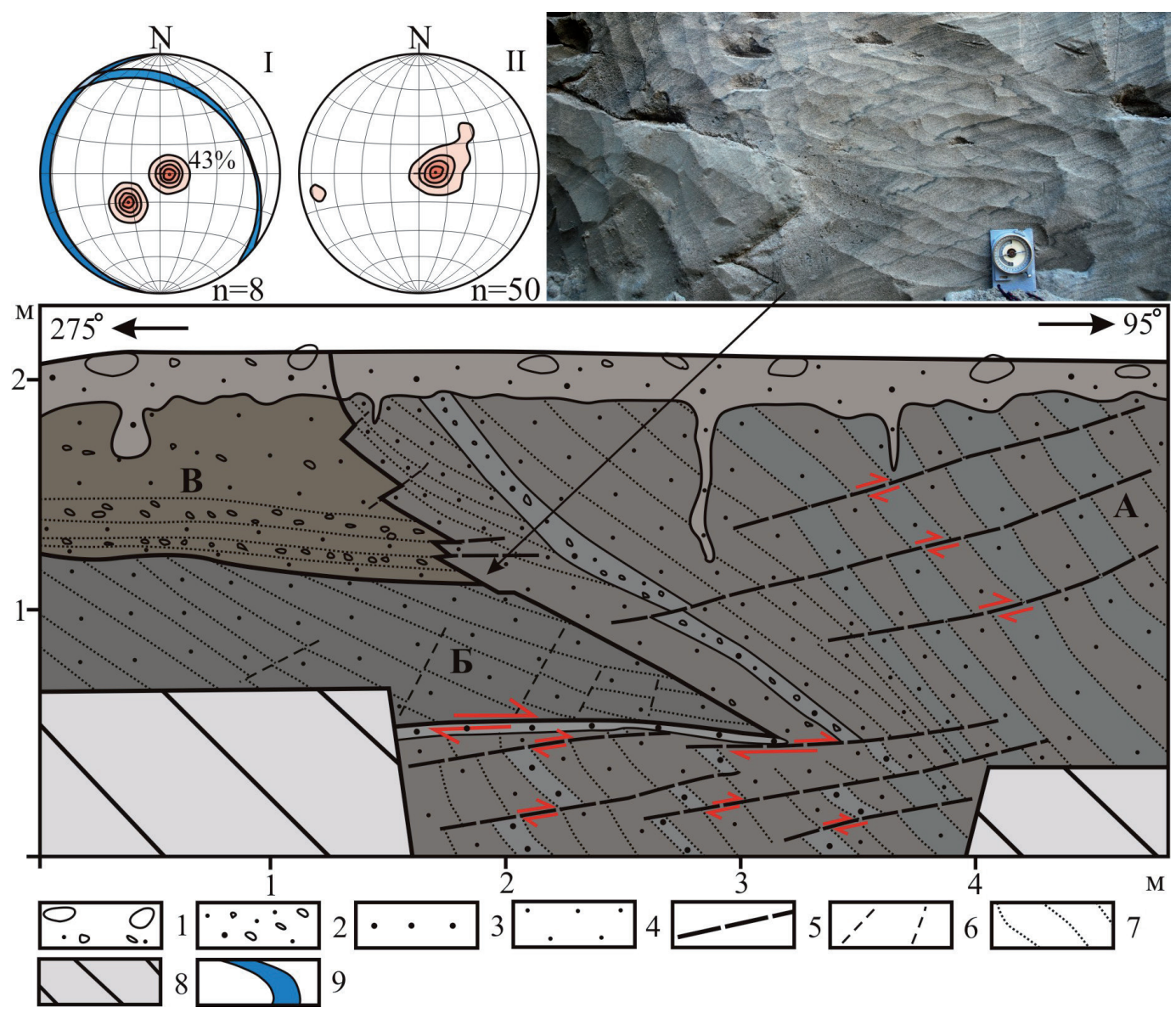

Рис. 2. Строение гряды у северо-западного склона г. Каменик (Панские Тундры): 1 - песок р.з., с гравием, галькой; 2 - песок р.з. с гравием; 3 - песок к.з. и с.з.; 4 - песок м.з.; 5 - субгоризонтальные зоны смещений первичной слоистости; 6 - то же, субвертикальные; 7 - направление падения слоистости; 8 - осыпь; 9 - проекции плоскостей смещений на нижней полусфере диаграмм.

Fig. 2. Structure of the ridge near the north-west slope of the Kamenik Mountain (the Pana Tundra): 1 - vari-grained sand with gravel and pebbles; 2 - vari-grained sand with gravel; 3 - coarse- and medium-grained sand; 4 - finegrained sand; 5 - subhorizontal zones of displacement of primary bedding; 6 - the same, subvertical; 7 - direction of dip of the bedding; 8 - talus; 9 - projections of displacement surfaces on the lower hemisphere of the diagrams. 
слоистые. Слоистость субпараллельная, волнистая. Вторая разность: пески р.з., преимущественно с.з., с примесью песка к.з., гравием и редкой галькой, светло-оливково-коричневые, слоистые. Слоистость субпараллельная, косая, падает преимущественно по азимуту $198^{\circ}$ под углом $14^{\circ}$. Общая видимая мощность осадков блока В - до 0.85 м.

Все отложения в шурфе дислоцированы разрывными нарушениями в виде пологих надвигов (разделяющих выделенные блоки осадков) с амплитудой смещения свыше 2.5 м, а также сколами, нарушающими первичную слоистость отложений. Сколы имеют амплитуду смещения от 1-2 см до 10 см. Падение полюсов плоскости сместителей этих нарушений установлено в двух направлениях для плоскостей надвигов - по азимутам $45^{\circ}$ и $260^{\circ}$. Для небольших сколов преобладает направление падения по азимуту $265^{\circ}$ (рис. 2, I, II).

В шурфе глубиной 2.1 м в 0.17 км к северо-востоку от описанного выше шурфа установлено подобное строение формообразующих осадков. В нижней части шурфа в строении также установлены алевриты однородные, уплотненные, зеленовато-серые, слоистые, с тонкими прослоями песков т.з. Мощность алевритов вскрытая - более 0.5 м. Выше по разрезу алевриты перекрыты песками т.з. и м.з., серого и оливково-серого цвета, слоистыми, с прослоями суглинков толщиной до 4 см. Контакт алевритов и песков падает по азимутам 188-202 ${ }^{\circ}$ и под углами 22-29 ․

Грядово-холмистый рельеф надстраивает поверхность равнины с абсолютными отметками 185-195 м, которая примыкает к склонам массива Панских Тундр. Её строение установлено в разрезе длиной 8 м и глубиной 2 м на борту долины ручья, левого притока р. Цага (N 67³3'21', E 3519'12', пункт b на рис. 1). Здесь под толщей песков оливково-коричневого цвета, т.3. и м.3. с примесью песков к.з. с гравием, мощностью до 0.5 м вскрываются пески р.з., преимущественно с.з., с гравием, галькой и валунами. Пески темно-серо-коричневого цвета, содержат примеси алеврита и глинистых частиц, несортированные, с отчетливой сланцеватой текстурой. В песках встречаются линзы серпообразной, извилистой формы, представленные песком м.з., светло-оливково-коричневым, слоистым. Слоистость выражена за счет прослоев песка р.з. с гравием. Толщина линз - до 0.2 м. Падение полюсов сланцеватости установлено в среднем по азимуту $310^{\circ}$ и под углами 7-14 ‥

Поверхность равнины осложняется грядами относительной высотой 5-16 м. Строение гряд разнородно. В шурфе на вершине гряды (рис. 1, пункт с) высотой 8-15 м вскрываются пески р.3., оливково-коричневого цвета, глинистые, с гравием, галькой, валунами и линзами песка м.з., однородного. Кровля и подошва разных линз имеет падение преимущественно по азимуту $235^{\circ}$, под углами $26-56^{\circ}$. В строении соседней формы на противоположном борту долины р. Цага (рис. 1, d) в строении холмистого массива высотой до 12 м вскрываются пески р.з., преимущественно м.з., с примесью гравия, гальки и валунов, светло-желто-коричневого цвета. В отдельных прослоях отмечаются супеси желто-коричневые, плотные, однородные, толщиной до 3 см, а также пески м.з., глинистые, толщиной до 10 см. Падение слоистости отмечается в среднем по азимуту $90^{\circ}$, под углами 3-5 ${ }^{\circ}$. В строении гряды, простирающейся параллельно ложбине с долиной р. Цага (рис. 1, е), вскрыты песчано-гравийно-галечные смеси с валунами, слоистые, плохо сортированные. Слоистость выражена за счет материала различной крупности. Падение границ слоев установлено по азимуту $210^{\circ}$, под углами $10-28^{\circ}$. В шурфе на поверхности гряды на западном берегу котловины оз. Вувъявр (рис. 1, f) вскрываются супеси светло-оливково-коричневого цвета, слоистые за счет прослоев песка т.з. и м.з., глинистого, оливкового цвета. Падение контактов слоистости установлено по азиму-

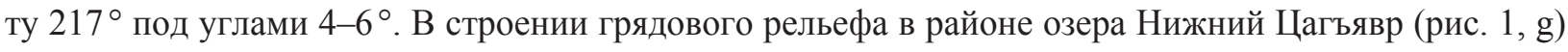
установлены пески т.з. и м.з., однородные, с прослоями алевритов, с волнистой слоистостью и многочисленными сколами, ориентировка которых совпадает с простиранием склонов гряд.

Интерпретация геологических и геоморфологических данных свидетельствует о формировании аккумулятивного рельефа района работ в несколько этапов, отражающих разные обстановки ледникового морфогенеза. Осадки, вскрытые в строении равнины, относятся нами к базальной морене. Эти отложения формировались в подледных условиях равномерного течения льда и отслоения его пластин, перенасыщенных дебрисом (Лаврушин, 1976). Такие условия отражают переход ледника из зоны талого к мерзлому ледниковому ложу (Каплянская, Тарногардский, 1993). 
В районе работ такие условия могли возникать при положении краевой зоны ледника на расстоянии 10-15 км восточнее в одну из фаз деградации последнего оледенения. Мощность ледника была небольшой, массив Панских Тундр не перекрывался покровным ледником. Этот массив не выступал в роли ядра аккумуляции гляциодислокаций большого масштаба вследствие относительно малой мощности ледника и его невысокой активности. Склоны массива являлись участком аккумуляции насыпных морен и маргинальных флювиогляциальных форм. Повторная подвижка ледника в одну из его фаз активации привела к деформации насыпных морен и флювиогляциальных осадков (рис. 2). Эта фаза сокращения ледникового покрова сопровождалась несколькими осцилляциями. Краткосрочным подвижкам ледника может соответствовать грядово-холмистый рельеф, исследованный в пунктах с и d (рис. 1). На заключительном этапе формирования ледникового рельефа фронтальная дегляциация сменилась на ареальную, что привело к омертвлению крупной полосы льда в бассейне современной р. Цага. Этот этап сопровождался аккумуляцией подледниковых озов (пункт g, рис. 1), надледниковых флювиогляциальных и лимногляциальных аккумуляций (валообразные гряды, пункты е и f на рис. 1) в условиях узких проталин вдоль отмершей краевой зоны ледника.

Таким образом, ледниковый рельеф района работ отражает положение одной из фаз деградации последнего оледенения в районе локальной ледораздельной зоны, в роли которой выступал массив Панских Тундр. Установлено, что дегляциация в этой части Кольского региона происходила поэтапно, этапы фронтального сокращения ледникового покрова сменялись ареальной дегляциацией. Продолжение данных работ с получением результатов абсолютного датирования насыпных морен и отложений, связанных с таянием мертвого льда, позволит установить возрастной ранг фазы сокращения ледникового покрова.

\section{Благодарности}

Авторы благодарят Н.В. Дёмину, Ю.С. Самсонову и А.В. Пуцкова за помощь в проведении полевых работ, а также О.П. Корсакову за обсуждение материала.

Работа выполнена по теме НИР 0226-2019-0054 лаборатории № 43 Геологического института КНЦ РАН.

\section{Литература}

1. Аболтиньш О.П. Гляциоструктура и ледниковый морфогенез. Рига. Изд-во: Зинатне. 1989. 284 с.

2. Государственная геологическая карта Российской Федерации. Масштаб 1: 1000000 (третье поколение). Серия Балтийская. Лист Q-(35), 36. Апатиты. Объяснительная записка (гл. ред. Ю.Б. Богданов). СПб. Изд-во: Картографическая фабрика ВСЕГЕИ. 2012. 456 с.

3. Евзеров В.Я. Горбунов Е.О., Колька В.В. Краевые ледниковые образования позднего дриаса в северной и центральной частях Кольского полуострова // Четвертичные отложения и новейшая тектоника ледниковый областей Восточной Европы. Апатиты. 1993. С. 26-38.

4. Евзеров В.Я., Николаева С.Б. Пояса краевых образований Кольского региона// Геоморфология. 2000. № 1. С. 61-73.

5. Каплянская Ф.А., Тарноградский В.Д. Гляциальная геология: Методическое пособие по изучению ледниковых образований при геологической съемке крупного масштаба. СПб. Изд-во: Недра. 1993. 328 с.

6. Лаврушин Ю.А. Строение и формирование основных морен материковых оледенений. М. Изд-во: Наука. 1976. 237 с.

7. Стрелков С.А., Евзеров В.Я., Кошечкин Б.И.,Рубинраут Г.С., Афанасьев А.П., Лебедева Р.М., Каган Л.Я. История формирования рельефа и рыхлых отложений северо-восточной части Балтийского щита Л. Изд-во: Наука. 1976. 164 с.

8. Ekman I., Iljin V. Deglaciations, the Younger Dryas End Moraines and their Correlation in Karelian A.S.S.R. and adjacent Areas // Eastern Fennoscandian Younger Dryas End Moraines. Field Conferencion, 1991. P. 73-101.

9. Hättestrand C., Kolka V., Stroeven A. The Keiva marginal zone on the Kola Peninsula, northwest Russia: A Key Component for reconstructing the palaeoglaciology of the northeastern Fennoscandian ice sheet // Boreas. 2007. V. 36. № 4. P. 352-370.

10. Kolka V., Korsakova O., Nikolaeva S., Yevzerov V. The Late Pleistocene interglacial, late glacial landforms and Holocene neotectonics of the Kola Peninsula // ICG excursion, № 34., August 14-23. 2008. 72 p. 